This article has been scanned by iThenticat No plagiarism detected

Volume 3, Issue 6, December 2021

p. 393-402

\title{
ASPECTS OF READING WEAKNESSES AMONG FIRST CYCLE STUDENT IN PRIVATE SCHOOLS IN SULTANATE OF OMAN
}

http://dx.doi.org/10.47832/2757-5403.6-3.28

Batoul Mohammed Saleh ALAJMI1 \& Fatma Abdullah Salim ALKINDI ${ }^{2}$

\begin{abstract}
:
This study aimed to identify the aspects of reading impairment among cycle one pupils at private schools in the Sultanate of Oman from their teacher's perspective and discover statistically significant differences in cycle one teacher's responses in those schools attributed to the governorate variable. In order to achieve the study's goal, the researchers used the descriptive method. The survey population included all cycle one teachers in private schools from governorate of AlBatinah South and North, Muscat and Al-Dakhiliyah. Responses of 500 teachers were received from those governorates. At the same time, among those teachers about 150 teachers were chosen randomly. They represent $30 \%$ to be the purposive sample. The researchers started to use a questionnaire to measure the degree of popularity of the aspects of reading impairment among cycle one pupils at private schools in the Sultanate Of Oman. This questionnaire is divided into three categories related to reading letters, words, and sentences.

It was revealed that the degree of popularity of the aspects of reading impairment among cycle one pupils at private schools in the Sultanate Of Oman from the cycle one teacher's perspective came to an average degree. However, there are no statistically significant differences at the level (0.05) among the teachers' responses according to governorate variable.

According to the study result, it is recommended to put more efforts in teaching reading skills in order to eradicate the common aspects of reading impairment. Related to these recommendations, it is suggested that conducting pilot studies aimed at testing proposed programs are
\end{abstract}

\footnotetext{
${ }^{1}$ Researcher, Sultan Qaboos University, Oman, s130802@student.squ.edu.om, https://orcid.org/0000-00020598-8172

${ }^{2}$ Researcher, Sultan Qaboos University, Oman, s129236@student.squ.edu.om, https://orcid.org/0000-0002$\underline{4525-1060}$
}

Copyright (C) Published by IJHER Journal, www.ijherjournal.com Rimar Academy, Fatih, Istanbul, 34093 Turkey

All rights reserved 
required to find out their effects to solve challenges resulted from aspects of reading impairment among cycle one pupils at private schools in the Sultanate Of Oman.

Key words: Reading Weakness, First Cycle, Private Schools, Sultanate of Oman.

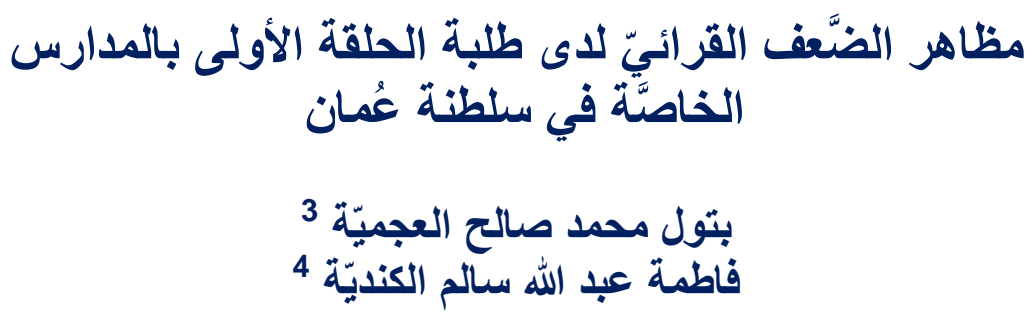

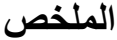

هدفت هذه الدراسة إلى التعرف على درجة شيوع مظاهر الضعف القرائي لدى طلبة

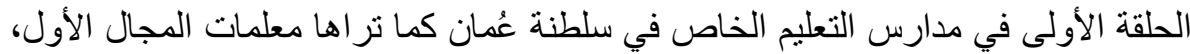

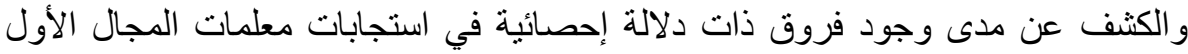
بخصوص مظاهر الضعف القرائي لدى طلبة الحلقة الأولى في مدارس التعليم الخاص في في التي

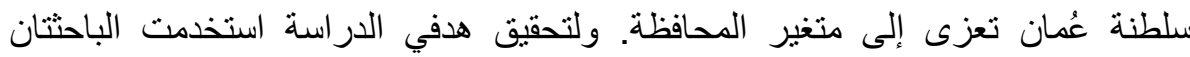
المنهج الوصفي، وتكوّن مجتمع الدراسة من جميع معلمات المجال الأول في المدارس

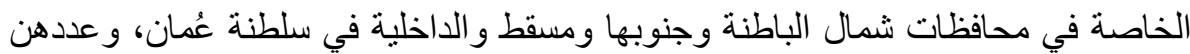
500 معلمة، وتكونت عينة الدراسة التي تم اختيارها بالتقنية العشوائية البسيطة من 150

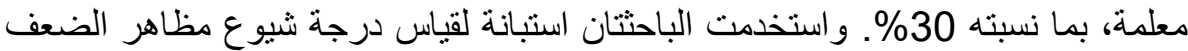

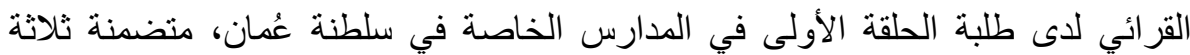
محاور: المحور الأول: مظاهر متعلقة بقراءة الحروف، والمحور الثاني: مظاهر متعلقة

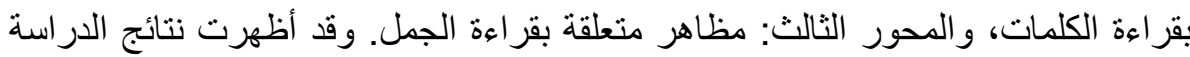

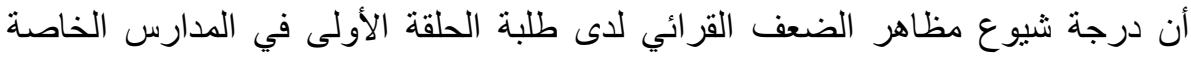

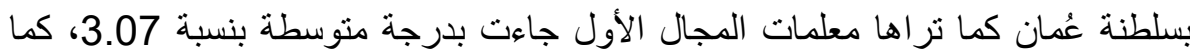

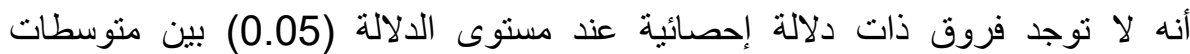

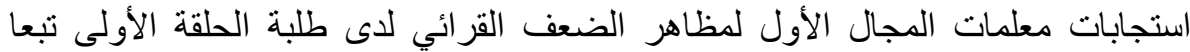

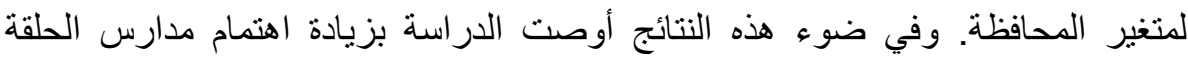

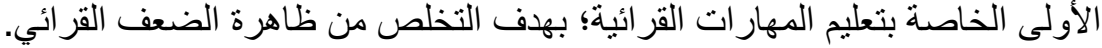
الكلمات المفتاحية: الضعف القرائي، الحلقة الأولى، المدارس الخاصة، سلطنة عمان.
\end{abstract}

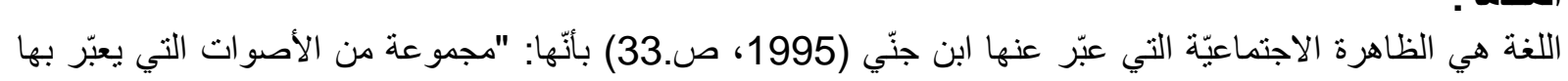

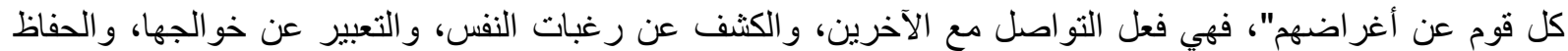

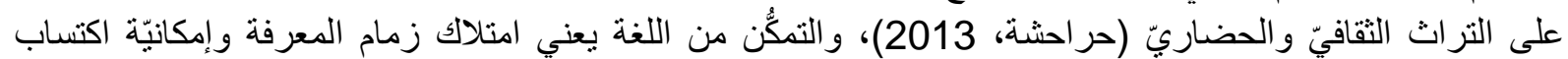

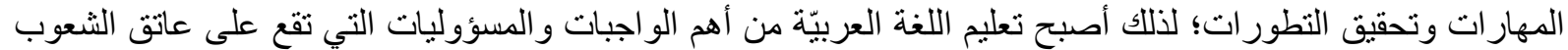

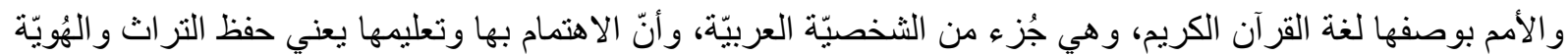

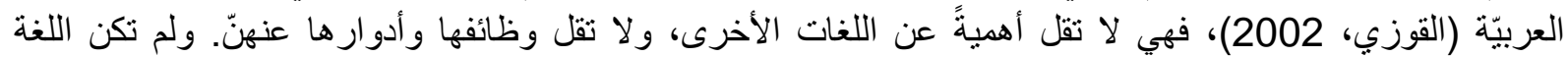

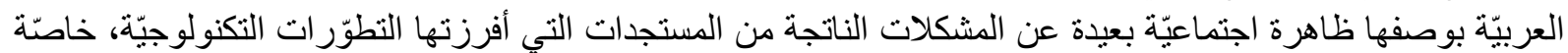




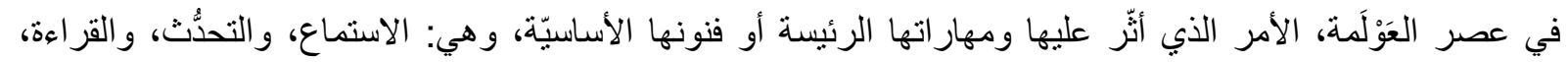

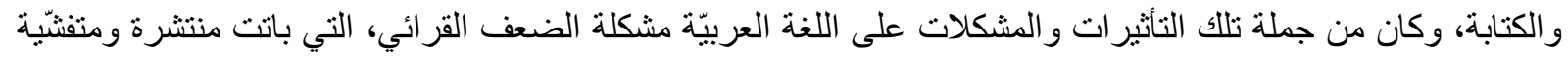

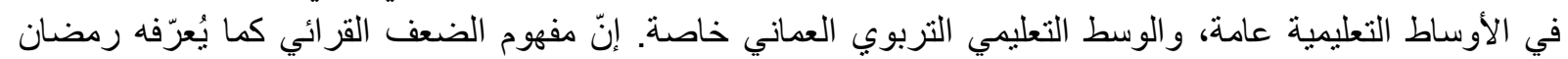

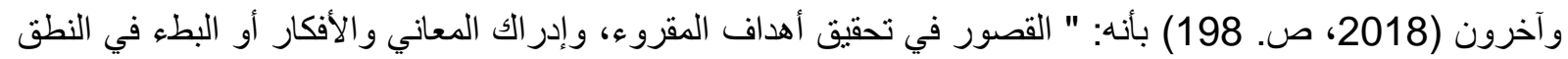

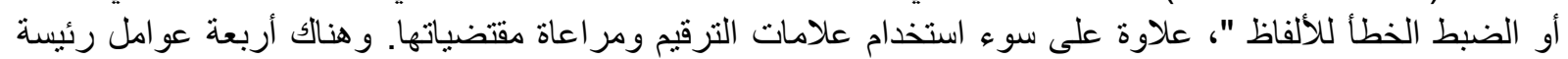

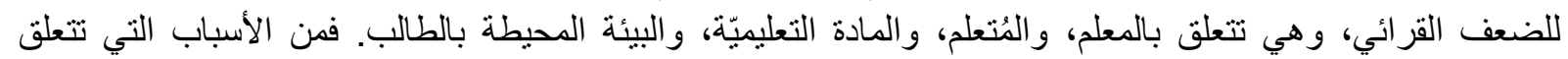

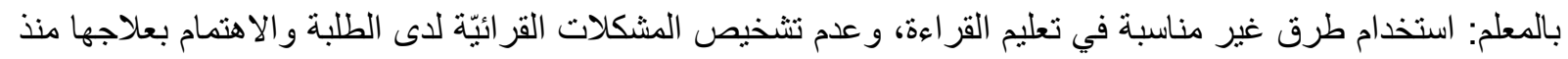

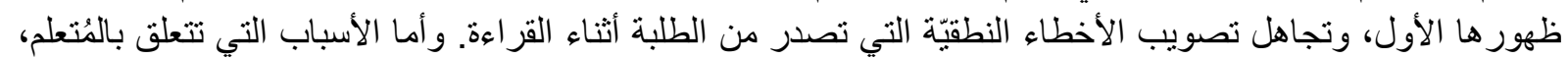

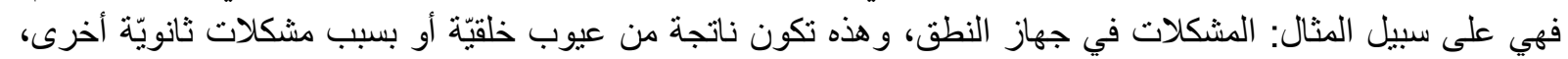

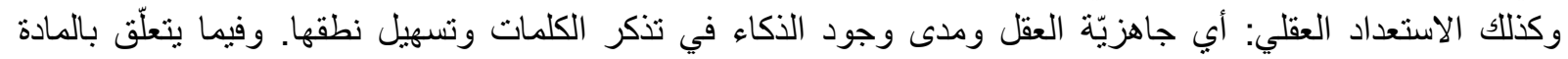

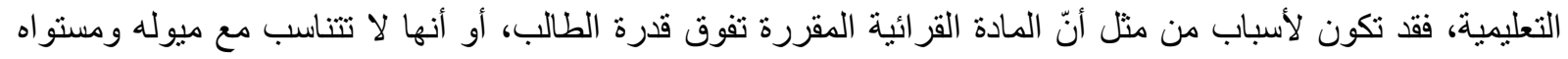

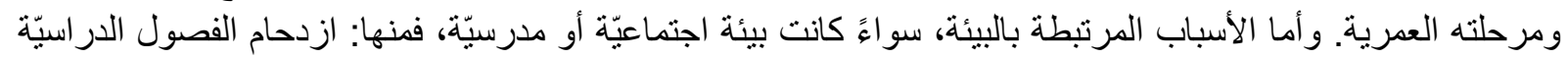

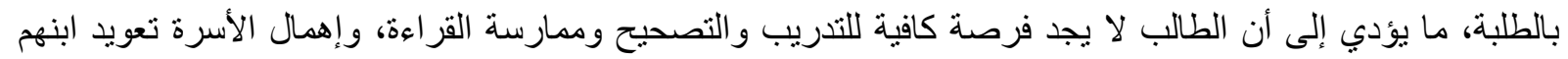

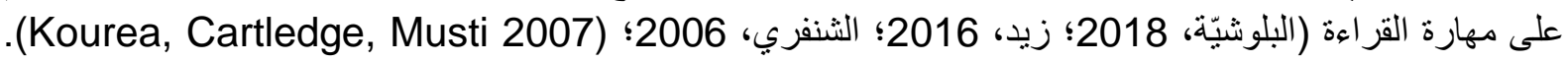
وتتخذ مشكلة الضعف القرائي مظاهر تتمثل في مهارتي النطق والتعرّف على التهى المكتوب، ويظهر هذا المظهر من خلال

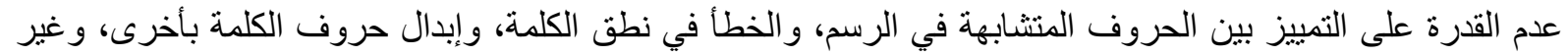

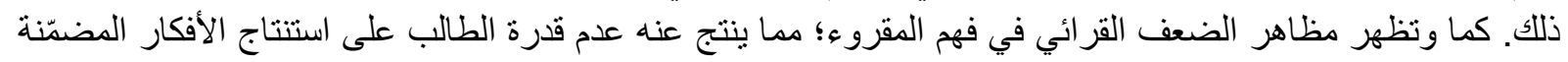

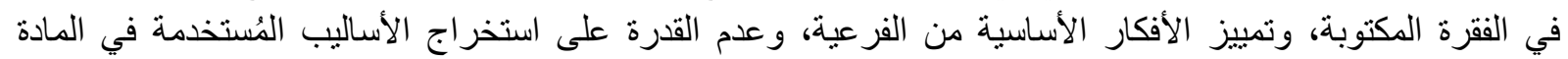

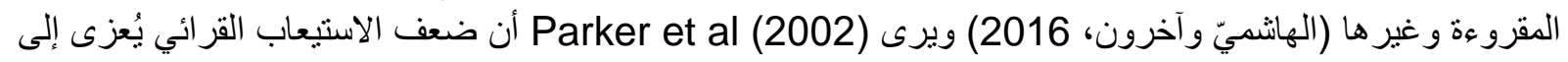

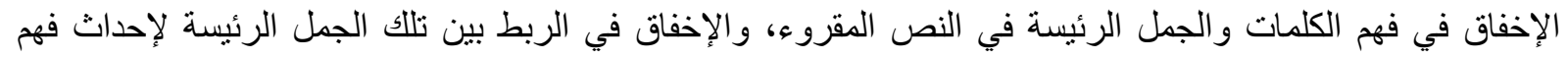

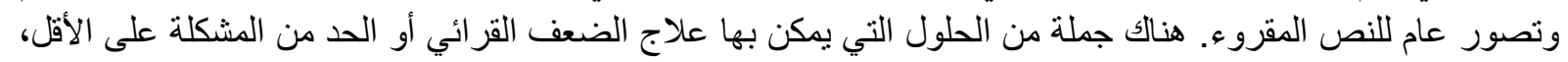

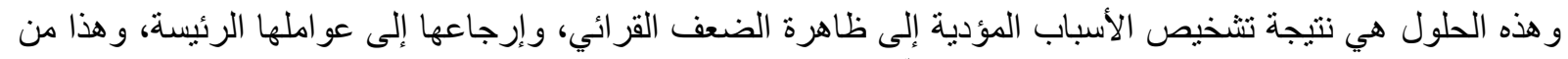

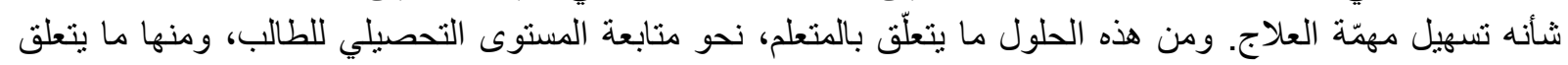

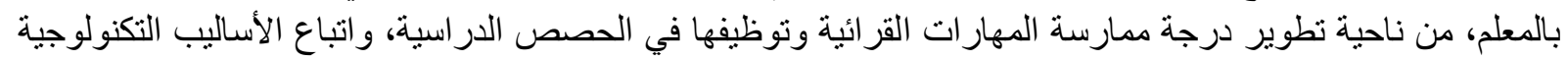

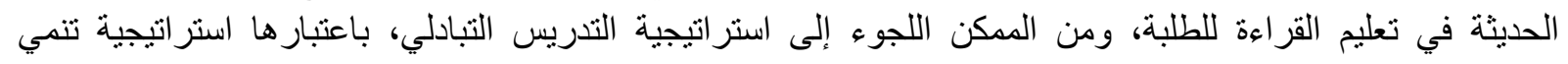

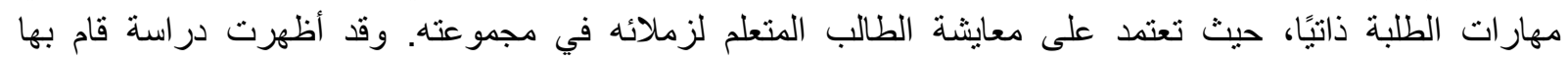

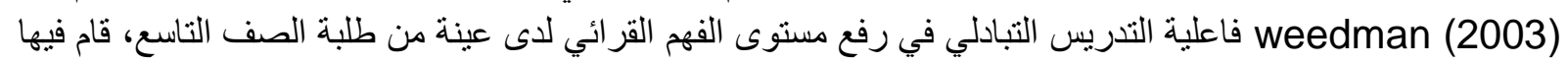

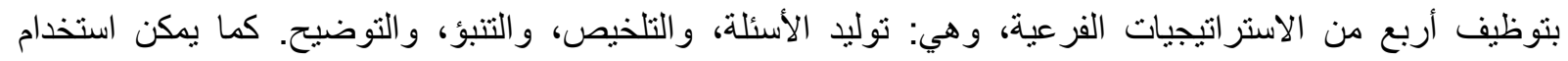

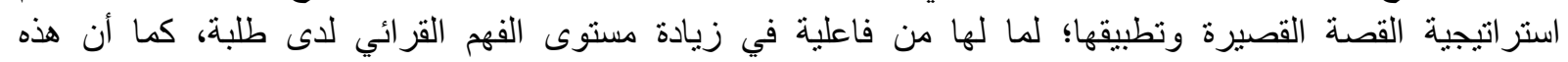

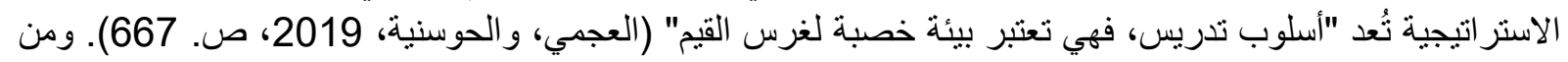

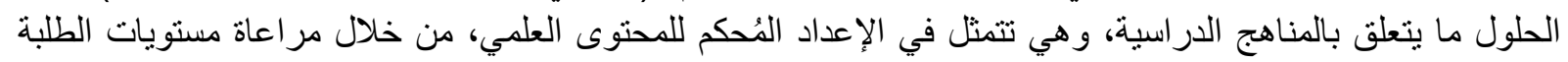

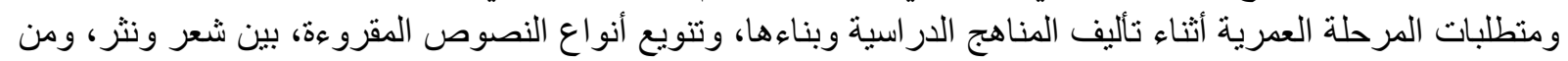

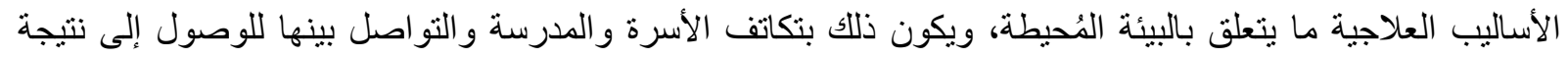

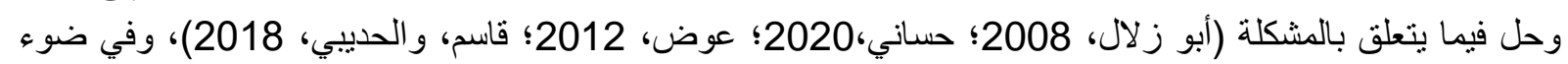

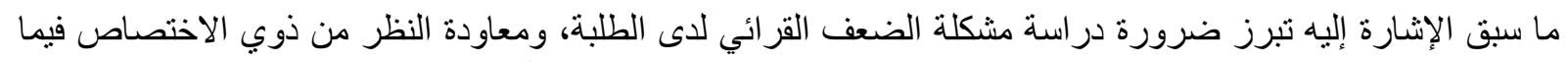

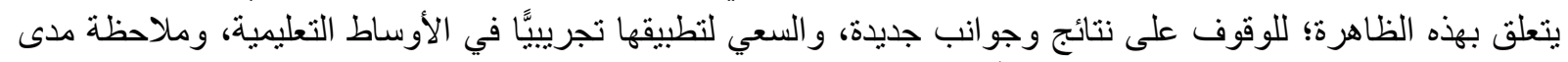

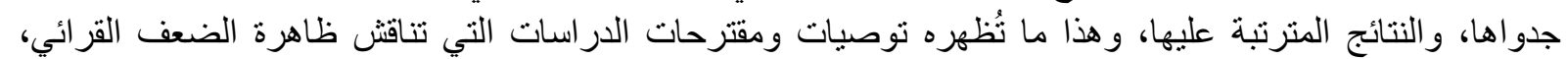

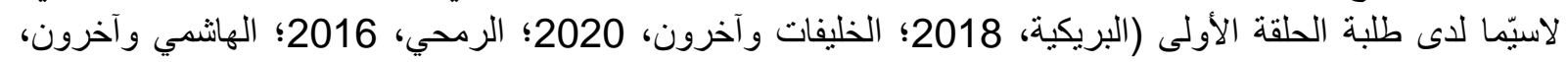

(2016

مشكلة الاراسة

تبذل وزارة التربية و التعليم جهودًا في سبيل علاج مشكلة الضعف القرائي، والتي تعد إحدى الظواهر المتفشيّة في الحقل

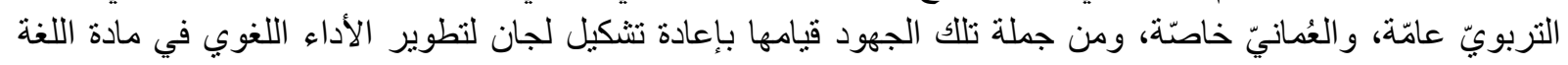




\section{ASPECTS OF READING WEAKNESSES AMONG FIRST CYCLE STUDENT}

IN PRIVATE SCHOOLS IN SULTANATE OF OMAN

العربية في الحلقتين الأولى و الثانية من التعليم الأساسي، وقيام اللجنة بتطبيق برنامج (أقر أ و أفكّر)، وتطبيق برامج تهدف

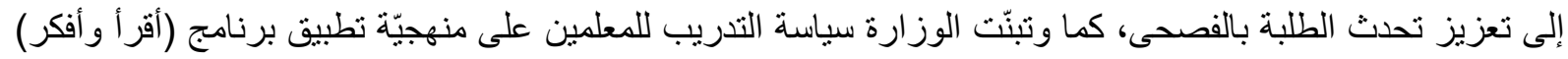

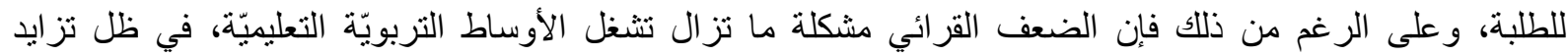

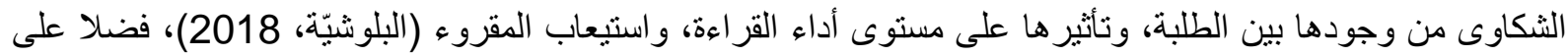

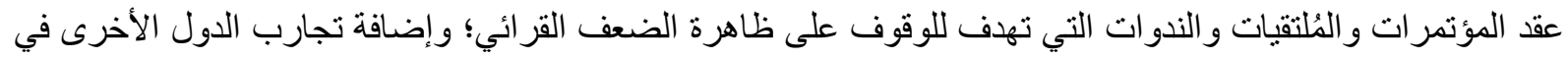

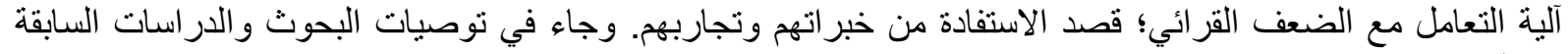

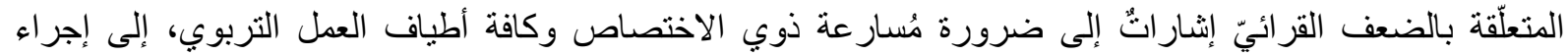

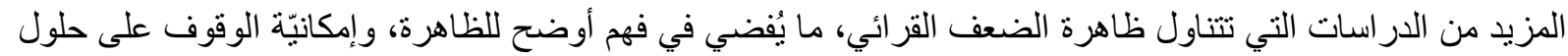

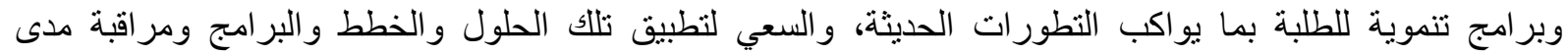

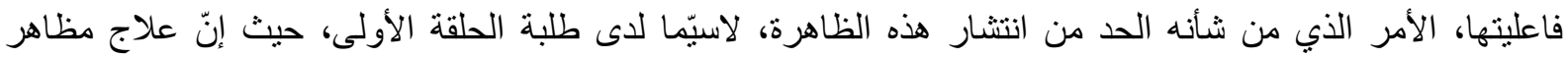

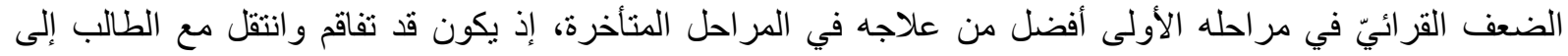

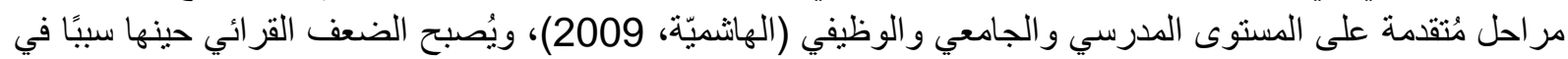

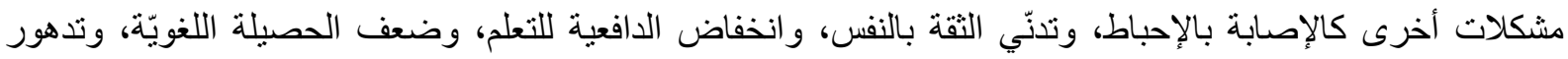

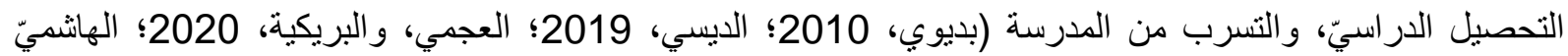

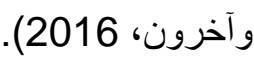

أسئلة الاراسة

1. ما درجة انتشار مظاهر الضعف القرائي وشيو عها بين طلبة الحلقة الأولى في المدارس الخاصة بسلطنة عُمان؟

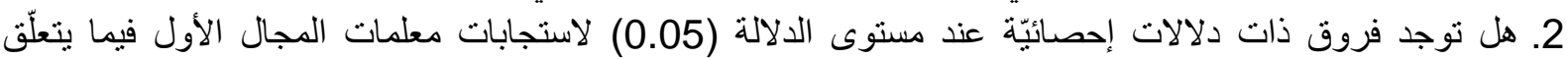

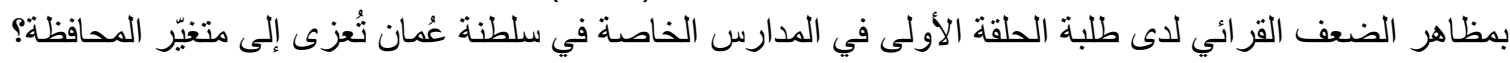

أهداف الاراسة

1. التعرف على درجة شيوع مظاهر الضعف القرائي ومدى انتشار ها لدى طلبة الحلقة الأولى بمدراس التعليم الخاص في سلطنة عُمان.

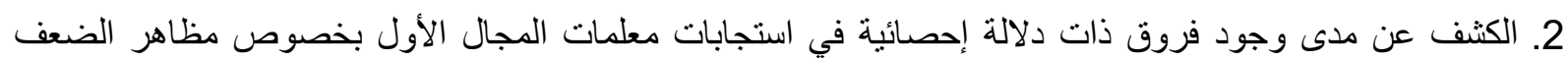
القر ائي لاى طلبة الحلقة الأولى بسلطنة عُمان نُعزى إلى متغيّر اليُحافظة.

أهميّة الاراسة

تكمن أهميّة الدر اسة في أهمّية مهارة القراءة في أبيّ لغة كانت، و أثثرها في تكوين جوانب من شخصية الإنسان الاجتماعية

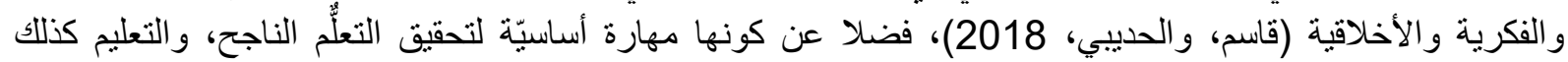

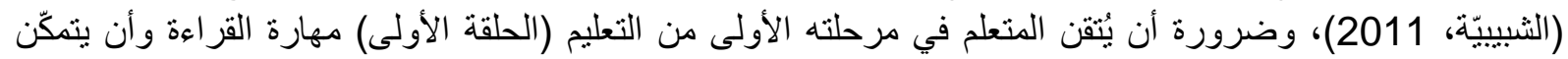

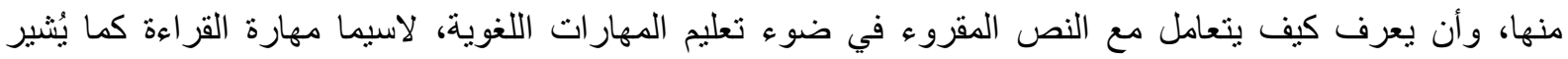
(Argo,1995; Barchers; 1994; Gavelek, 1999) أساسها القر اءة، وكذلك اكتساب عادات جديدة تُشكّل عقله، وتصقل شخصيّته (زاير، و وهاثم، 2016). كما وتكمن أهيّة

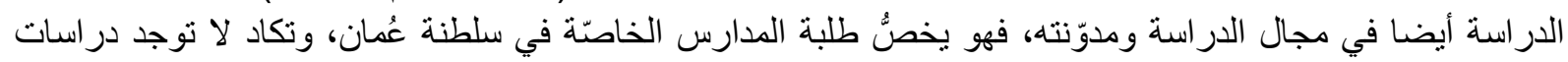

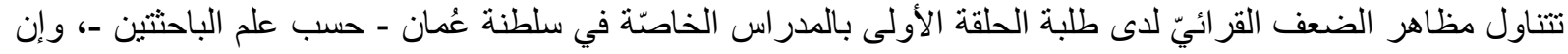

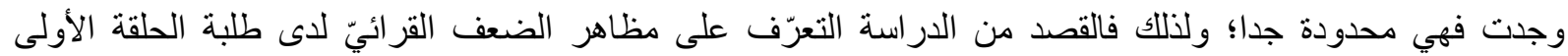

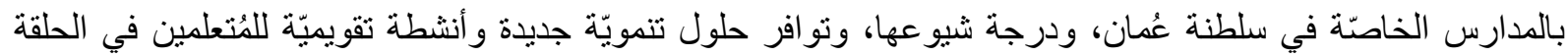
الأولى بالمدارس الخاصيّة. 
1. الحدود الموضوعيّة: تتمثل في مظاهر الضعف القرائيّ.

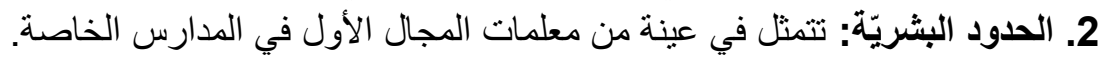

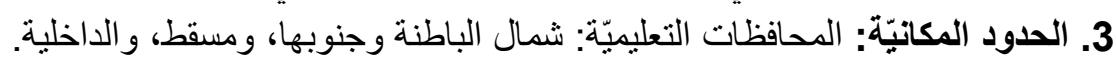

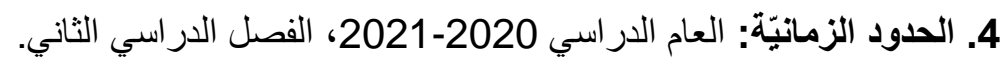

مصطحات الاراسة

1. مظاهر: لغة من مادة (ظََهَرَ)، وفي المعجم الوسيط المظهر: "الصورة التي يبدو عليها الثيء، ...." (مجمع اللغة

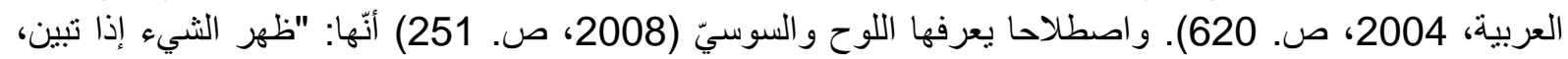

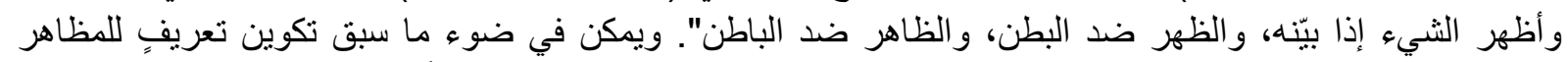

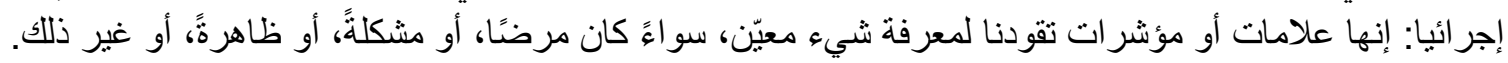

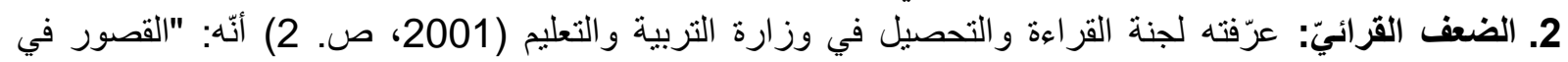

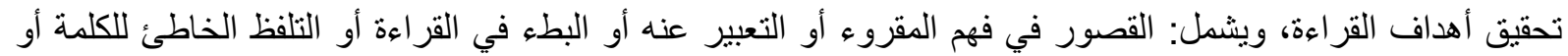

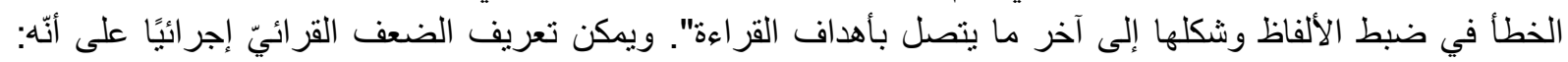

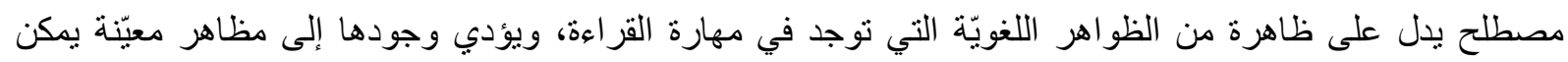

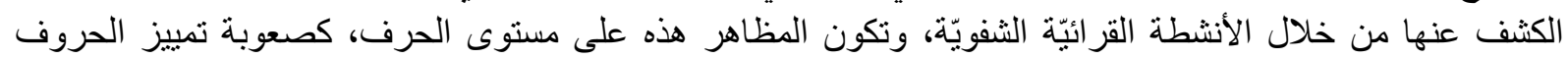

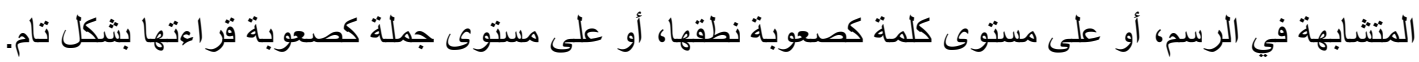

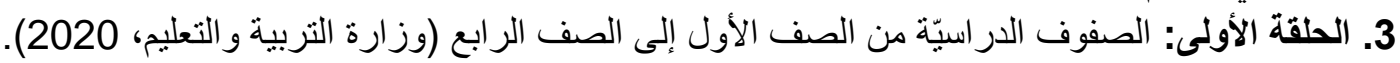

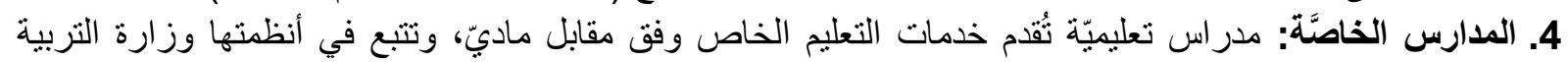
و التعليم (وزارة التربية والتعليم، 2020).

منهج الاراسة

منهج هذه الدر اسة هو المنهج الوصفيّ التحليليّ؛ إذ هو من المناهج المناسبة للتعامل مع ظاهرة الضعف القرائيّ واسيّ واستخدام

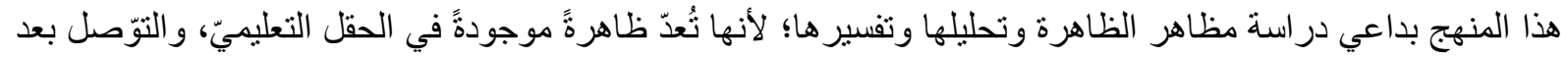

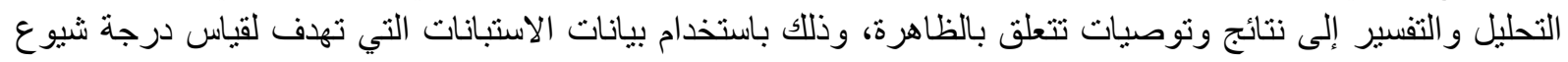
مظاهر الظاهرة المدروسة لدى العيّنة المحدة (علام، 2012)، من خلال المحاور التي تتضمنها الاستبانات.

\section{مجتمع الاراسة والعينة}

تكون مجتمع الدراسة من جميع معلمات المجال الأول في المدارس الخاصة في سلطنة عُمان، في محافظات: شمال

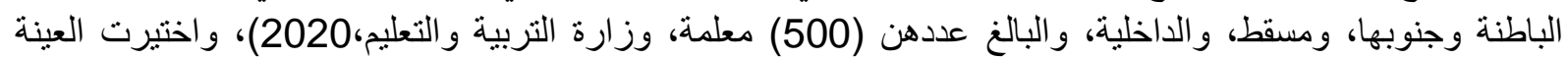
بالطريقة العشو ائية البسيطة، وقد شكلت ما نسبته 30\% من مجتمع الدراسة، واشتملت على 150 معلمة.

أداة الدراسة

للتعرف على درجة شيوع مظاهر الضعف القرائي لاى طلبة الحلقة الأولى في المدارس الخاصة بسلطنة عُمان، ثم اقتباس

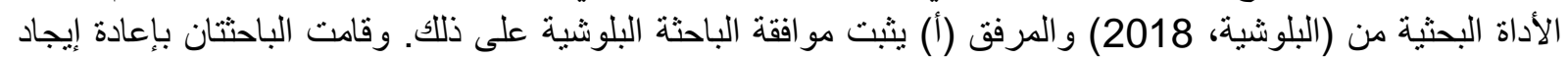

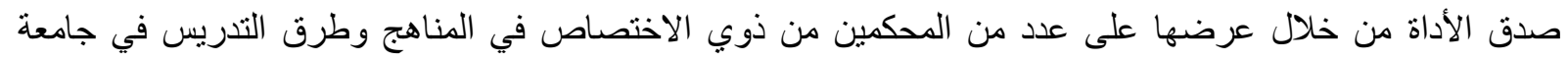

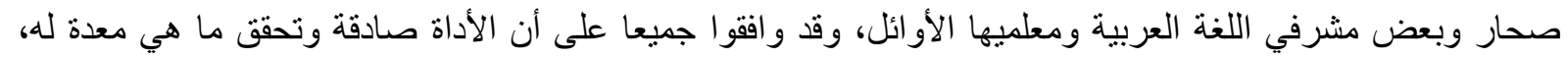

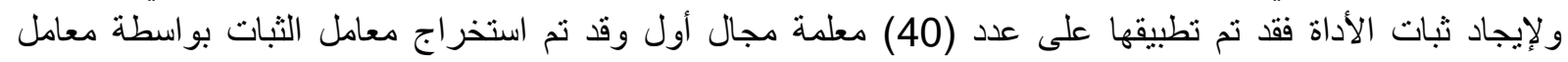

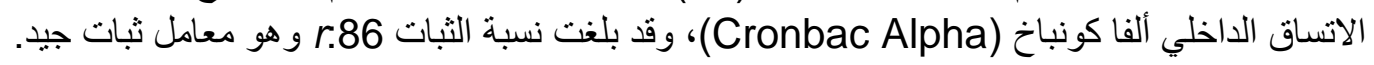


إجر اء مسح للأدب التربوي، والبحوث و الدراسات السابقة ذات العلاقة بالضعف القرائي، والإفادة منها في كتابة الإطار

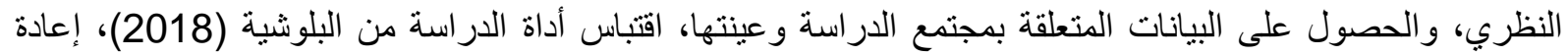

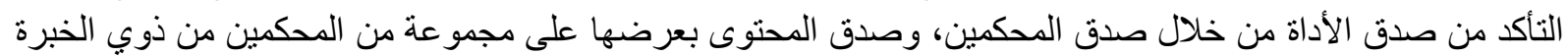

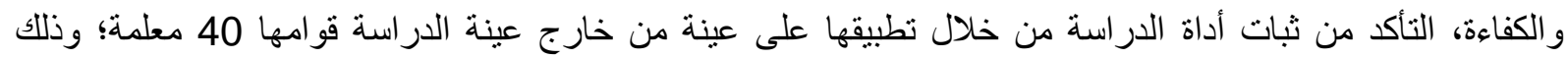

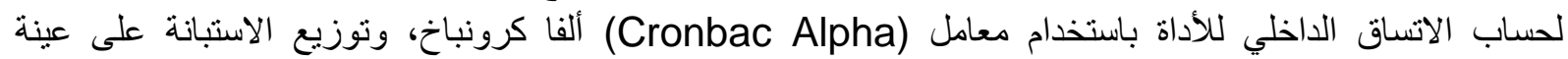

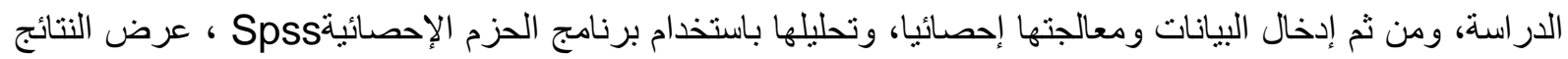

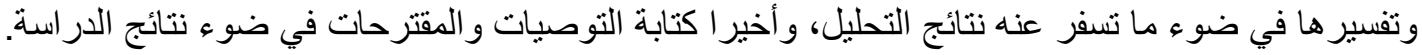

المعالجات الإحصائية

قامت الباحثتان باستخدام برنامج الحزم الإحصائية في العلوم الاجتماعية (Spss) لمعالجة البيانات التي نم التوصل إليها

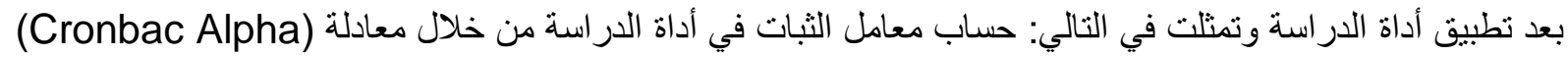

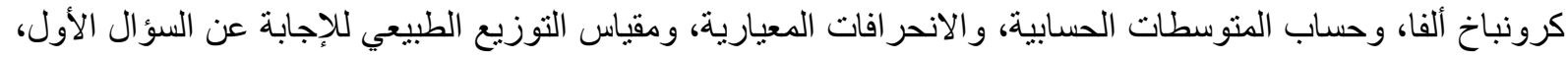

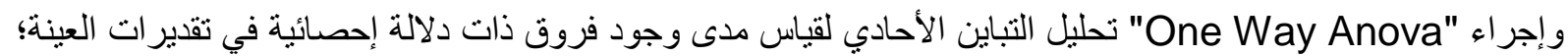

ل إلجابة عن السؤال الثاني.

مناقشة النتائج

1. للإجابة عن السؤال الأول والذي نص على: ما درجة انتشار مظاهر الضعف القرائي وشيوعها بين طلبة الحلقة

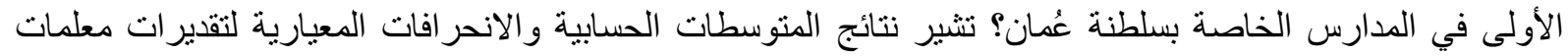

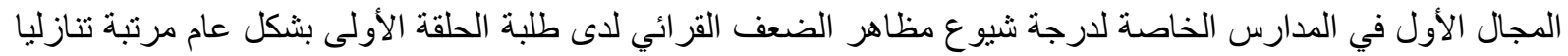

حسب المتوسط الحسابي، كما يوضحها الجدول 1.

جدول 1 المتوسطات الحسابية والانحر افات المعيارية لارجة شيوع مظاهر الضعف القرائي لاى طلبة الحلقة الأولى كما تر اها معلمات المجال الأول في المدارس الخاصة

\begin{tabular}{|c|c|c|c|}
\hline الشيوع مستوى & الانحر افات & المتوسطات & المحاور \\
\hline متوسطة & .417 & 3.10 & المظاهر المتعلقة بقر اءة الحروف \\
\hline متوسطة & .584 & 3.25 & المظاهر المتعلقة بقر اءة الكلمات \\
\hline متوسطة & .790 & 2.87 & المظاهر المتعلقة بقراءة الجمل \\
\hline متوسطة & .823 & 3.07 & المجموع \\
\hline
\end{tabular}

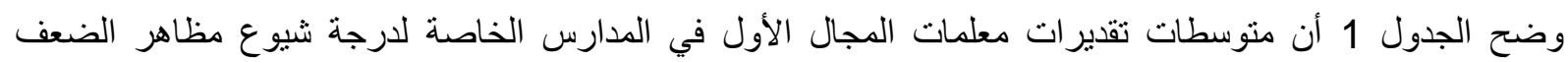

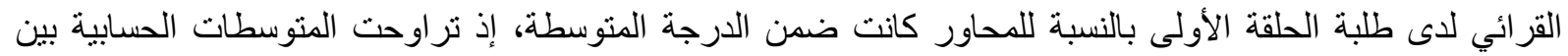

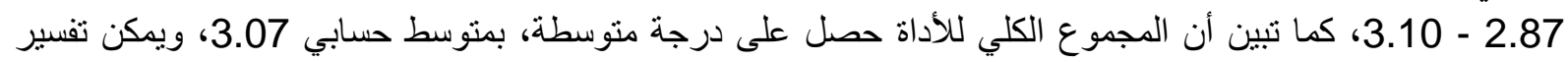

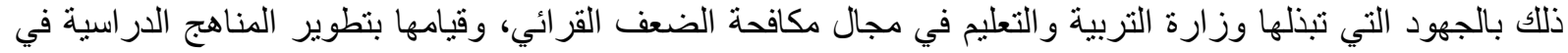

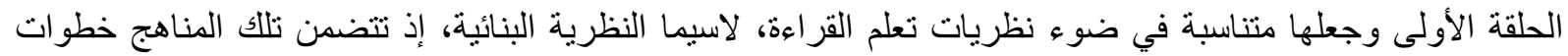

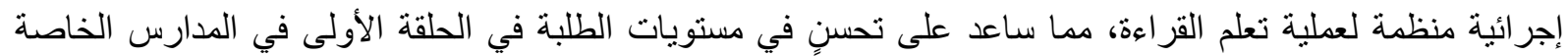

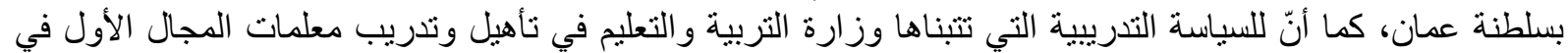

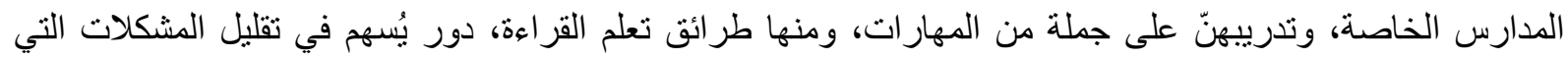

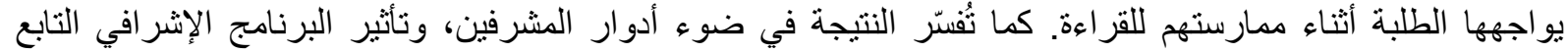

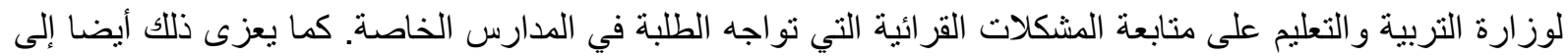

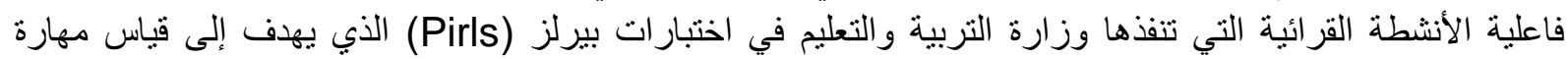

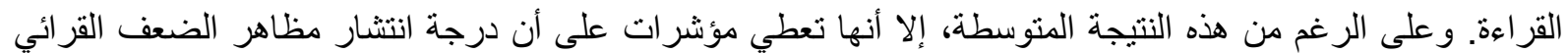


بين طلبة الحلقة الأولى في المدارس الخاصة بسلطنة عُمان تحتاج إلى مزيد من الجهود النوعية من قِبل وزارة التربية

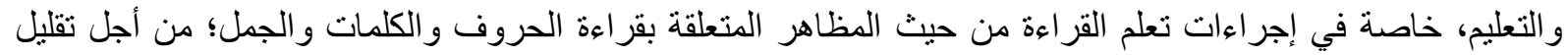

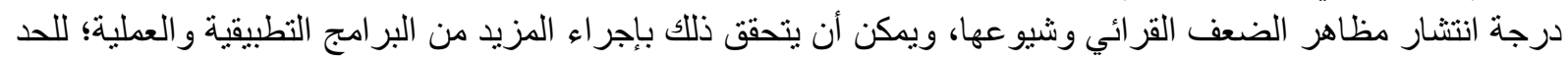

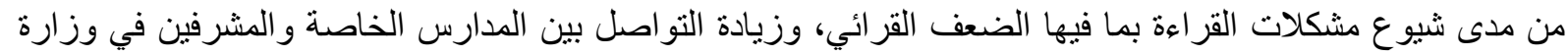

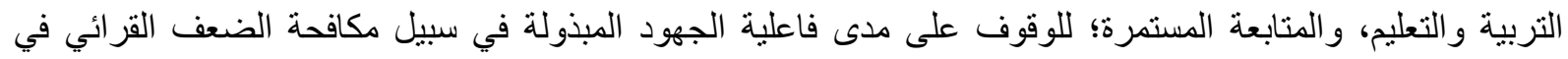

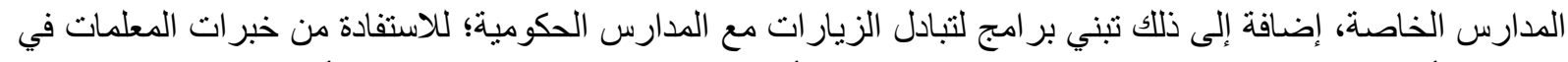

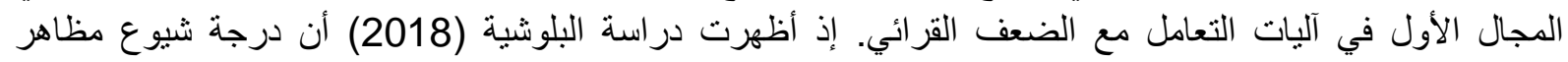

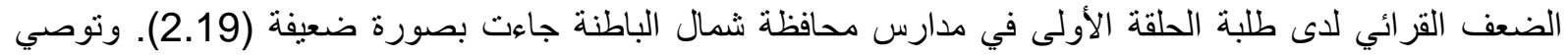

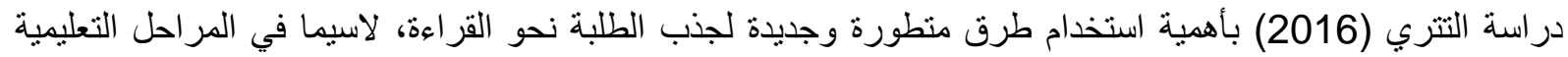

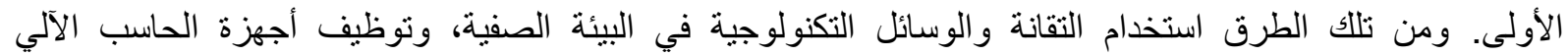
و الاستفادة منها في تعليم القراءة، والتي من شأنها الإسهام في تحقيق الأهداف التعليمية، وجعل عملية تعلم القراءة أسهل

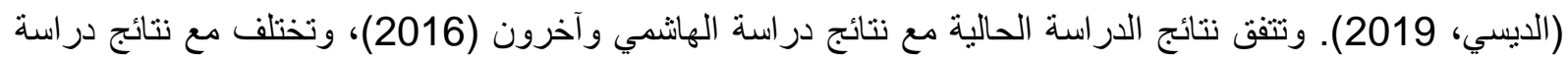

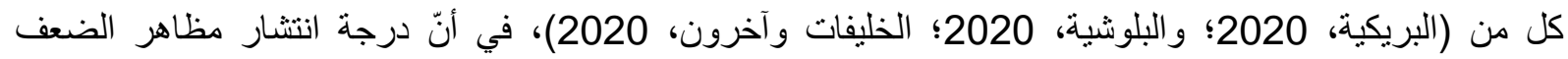
القرائي وشيوعها بين طلبة الحلقة الأولى ضعيفة في الدراستين الأولى والثانية، ودرجة الانتشار مرتفعة في الدراسة

2. للإجابة عن السؤال الثاني والأي نص على الآتي: هل نوجد فروق ذات دلالات إحصائيّة عند مستوى الدلالة (0.05)

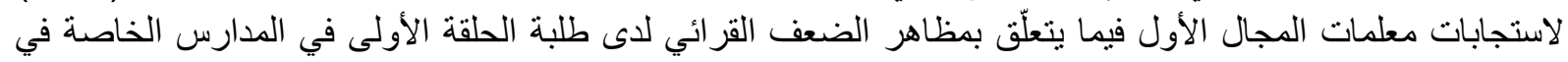

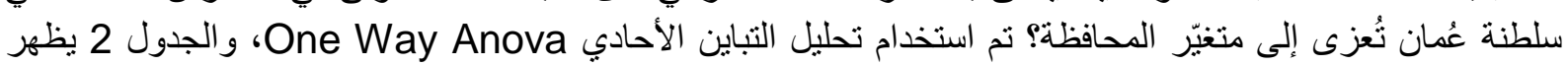
نتائج التحليل. جدول 2 نتائج تحليل التباين الأحادي للفروق بين منوسطات استجابات معلمات المجال الأول لمظاهر الضعف القرائي

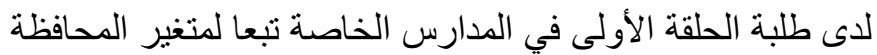

\begin{tabular}{|c|c|c|c|c|c|}
\hline مستوى الدلاكة & قيمة ف & المربعات & درجات الحرية & مجموع المربعات & مصدر التباين \\
\hline .507 & .863 & $\begin{array}{l}.209 \\
.233\end{array}$ & $\begin{array}{c}5 \\
254 \\
259\end{array}$ & $\begin{array}{c}2.053 \\
60.981 \\
63.034\end{array}$ & داخل المجموعات المجموعات \\
\hline
\end{tabular}

بيّن الجدول 2 أنه لا توجد فروق دالة إحصائيا عند مستوى الدلالة (0.05) بين متوسطات استجابات معلمات المجال

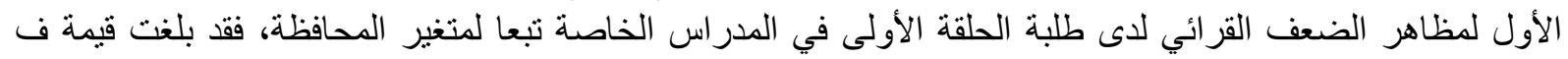

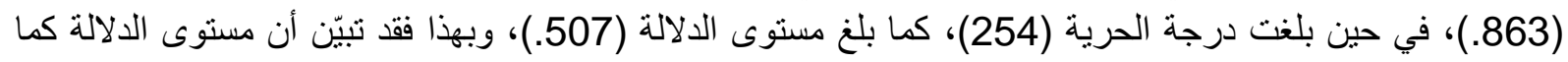

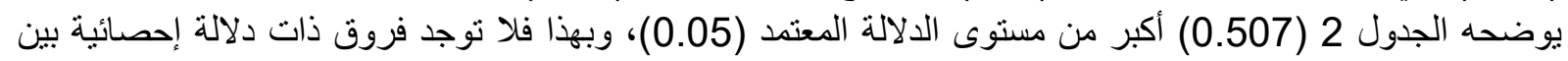

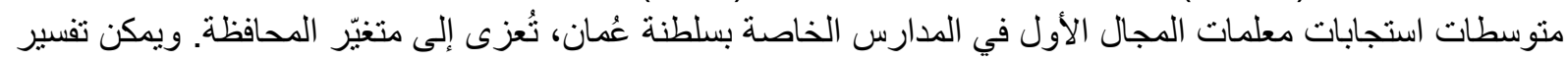

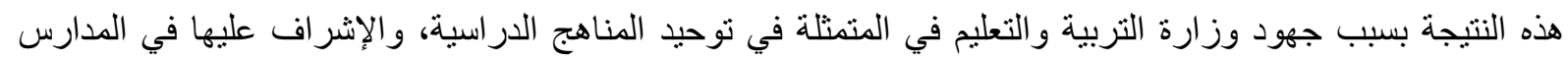

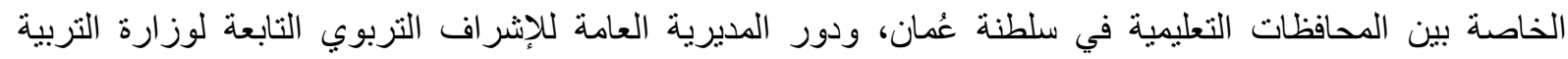

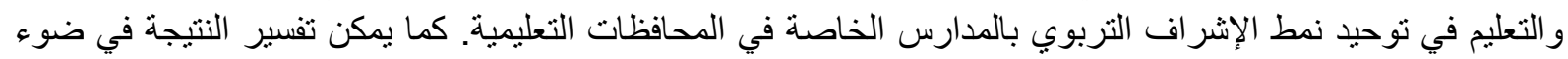

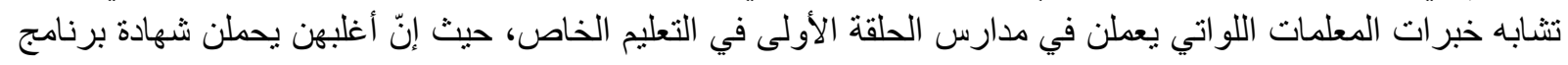

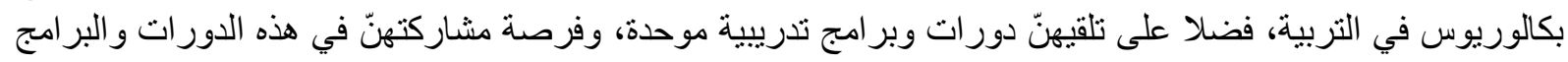

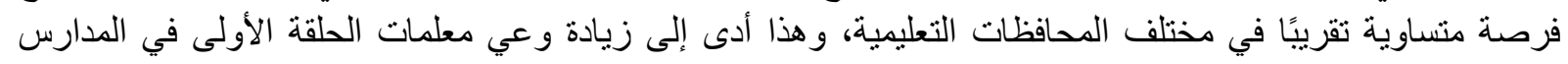

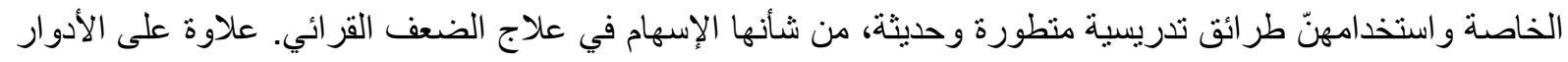

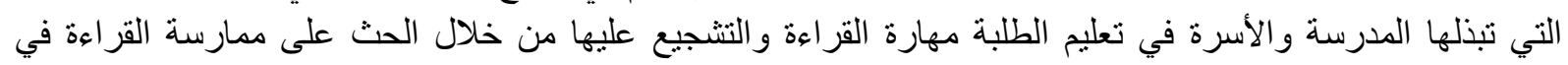

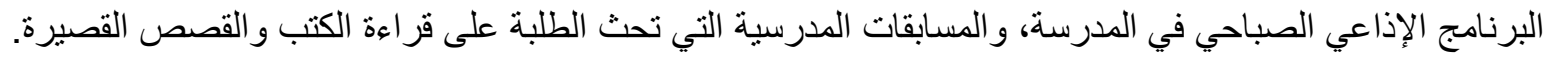


1. تركيز مشرفي المجال الأول في المدارس الخاصة أثناء زياراتهم الصفية على متابعة مستويات القراءة لاءى طلبة

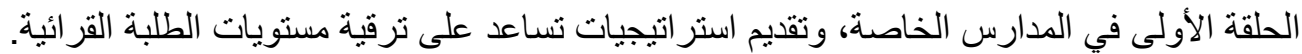

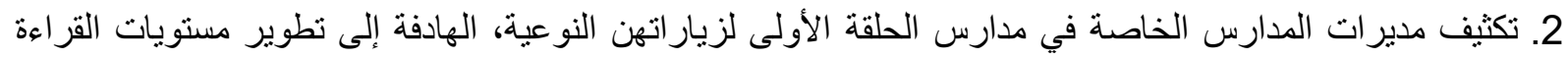

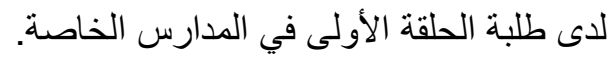
3. إجراء تبادل زيار ات مع مختلف المحافظات التعليمية؛ للاستفادة من خبرات بعض المحافظات التعليمية التي لم تشملها الأدرا. 4. إلحاق معلمات المجال الأول في المدارس الخاصة بمزيد من الدورات التدريبية التي تركز على الاستراتيجيات الحديثة في تعليم القر اءة لطلبة الحلقة الأولى.

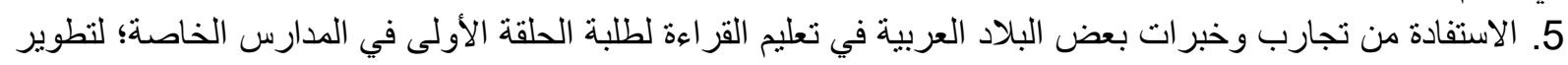

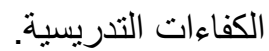
6. زيادة التنسيق بين الأسرة و المدرسة في تعزيز مستويات القراءة الفاعلة لاى طلبة الحلقة الأولى في المدارس الخاصة. المقترحات 1. القيام بدر اسات مقارنة بين بقية المحافظات التعليمية التي لم تشملها الدراسة؛ بهدف تعرف مستويات الضعف القرائي في جميع المحافظات التعليمية. 2. إجراء دراسات تجريبية تهدف إلى تطبيق استر اتيجيات تدريسية؛ لقياس أثر ها على تطور مستويات القراءة لدى طلبة الحلقة الأولى في المدارس الخاصة.

المصادر والمراجع ابن جنيّ، أبو الفتح. (1995). الخصائص. (ط.2.2008. دار الكتاب العربي.

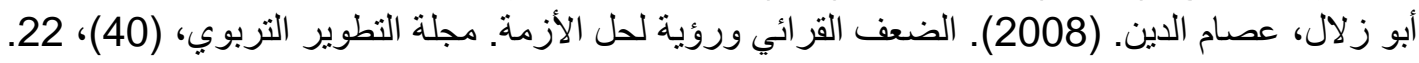

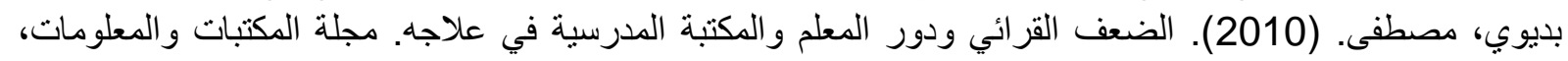
.43-31،(4)

البريكيّة، آمنة. (2018). مظاهر الضعف القرائيّ لدى طلبة الحلقة الثانية من التعليم الأساسيّ بمحافظة جنوب الباطنة كما

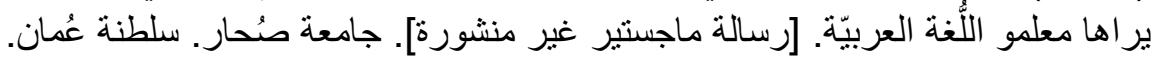

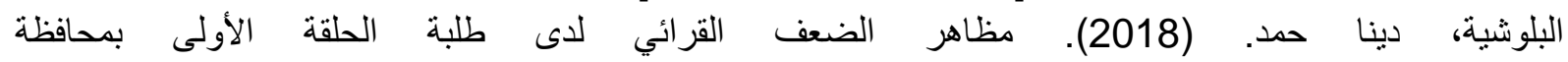
شمال الباطنة كما تر اها معلمات المجال الأول. [رسالة ماجستير غير منشورة]. جامعة صُحار. سلطنة

بني ذياب، محمود عوض. (2011). فاعلية طريقة التدريس التبادلي لمادة النصوص الأدبية في علاج ضعف الطلبة في 19 الناب

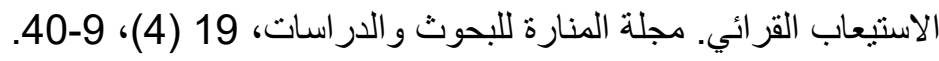

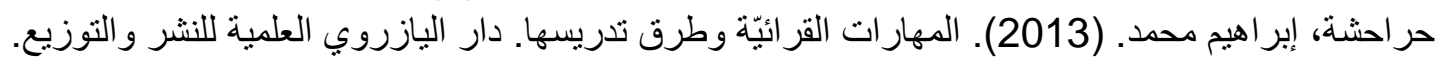

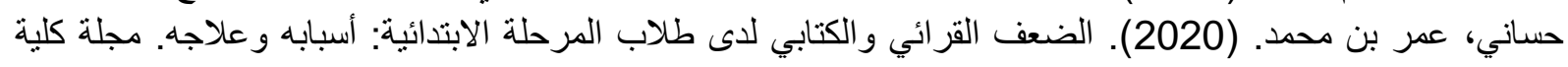
النزبية، 36 (4)، (207-87).

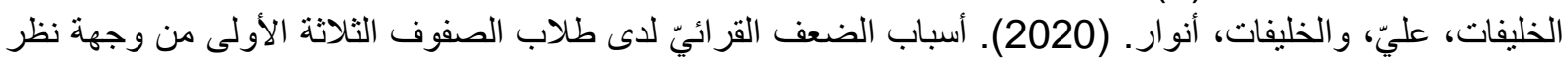

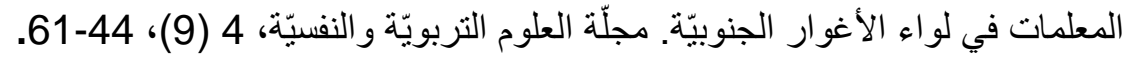

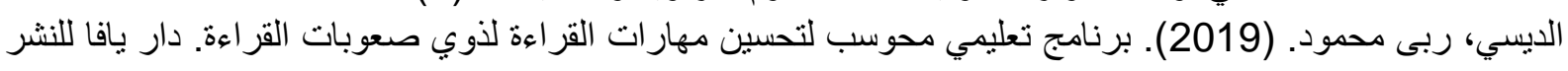
و التوزيع.

الديسي، ربى محمود. (2019). مدخل إلى صعوبات القر اءة: الديسلكسيا. دار يافا للنشر و التوزيع.

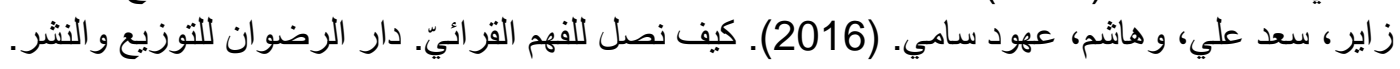


زيد، ميرا محمد. (2016). أسباب تدنّي مستوى القراعة ومُقترحات علاجها في المدارس الأساسيّة من وجهات نظر

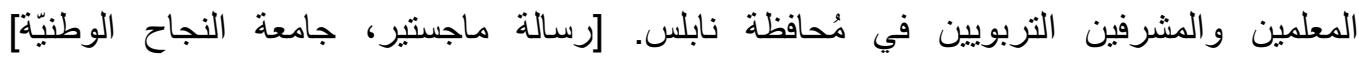
.https://scholar.najah.edu/sites/default/files/Mira\%20Zeid_0.pdf السوسيّ، ضيائي، واللوح، عبد السلام. (2008). مظاهر الفساد وآثاره في ضوء القرآنان الكريم. مجلّة جامعة الأزهر، 247-278، (10)1

الشنفري، سهيل. (2006). الضعف القرائي دراسة أجرتها وزارة التربية والتعليم حول: الضعف القرائي في الحلقة

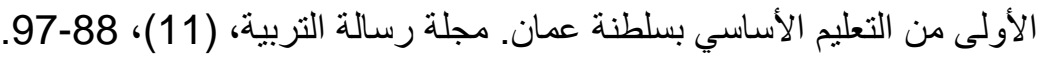

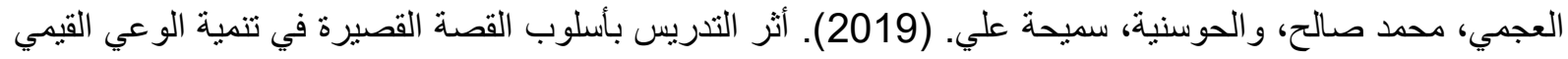

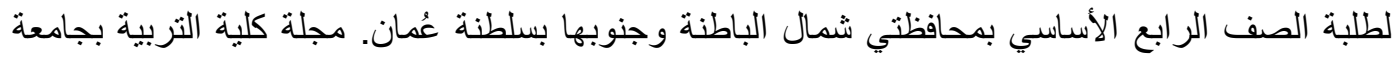

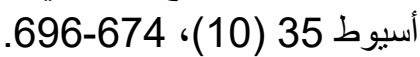

العجمي، محمد صالح، والبلوشيّة، دينا حمد. (2020). مظاهر الضعف القيّة القرائيّ لدى طلبة الحلقة الأولى بمُحافظة شمال

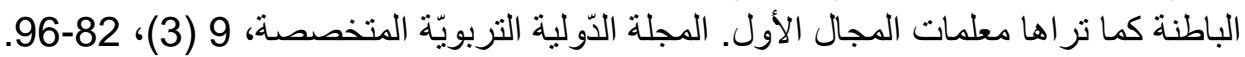

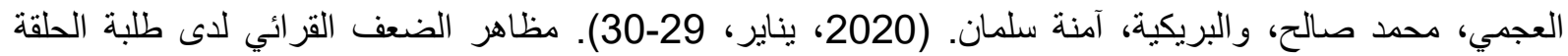

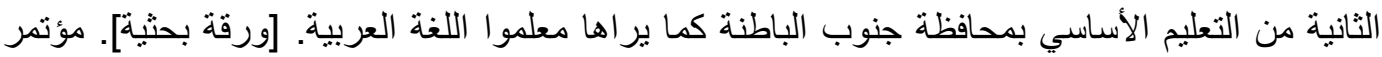
اللغة العربية الدولي الرابع بالثارقة.

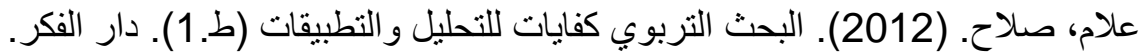

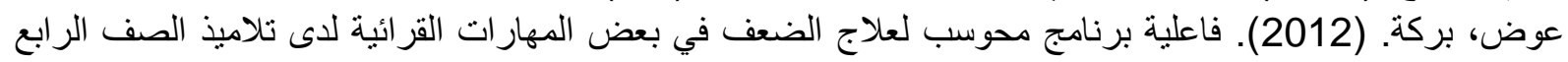

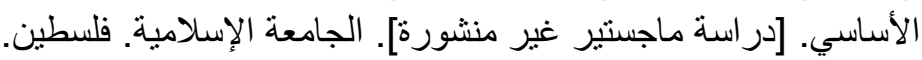

قاسم، محمد جابر، والحديبي، علي عبد المحسن. (2018). استراتيجيات تدريس اللغة العربية. المركز التربية. التربوي للغة

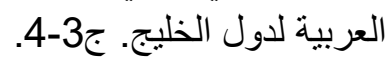

القوزي، عوض. (2002). مناهج تعليم اللغة العربية. معهد الدراسات و الأبحاث للتعريب، 1، 43-62.

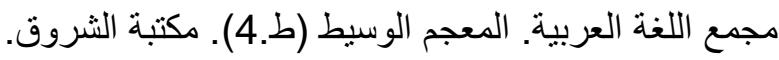

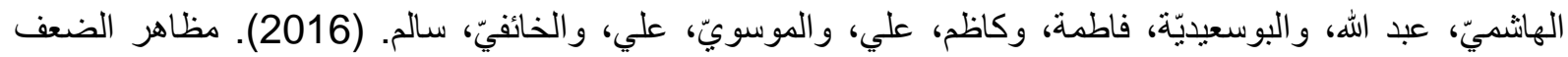

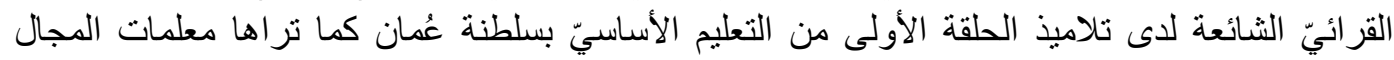

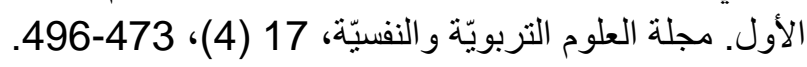

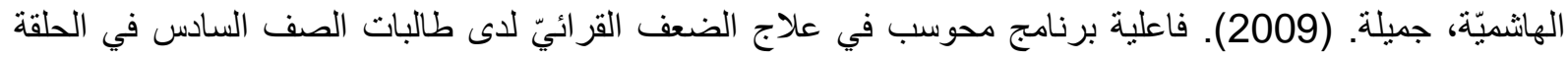

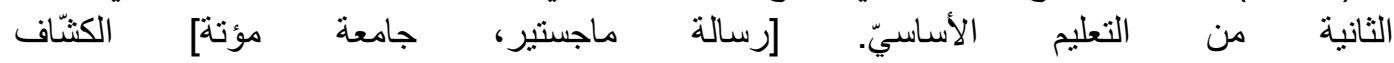
.http://thesis.mandumah.com/Record/207474/Details

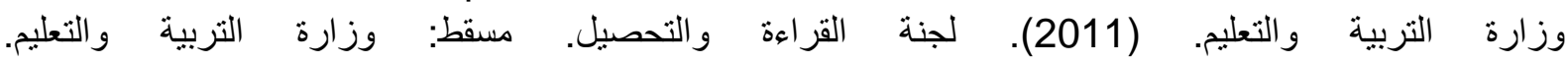
.https://home.moe.gov.om

وزارة التربية و التعليح. (2020). المديرية العامة للمدراس الخاصة. Gradps:/home.moe.gov.om.

Argo, D. (1995). A Study of the Achievement of Sixth Grade Students In An Integrated Language Arts Programe, Fort Hays Starte University, Kansas. ED 384048.

Barchers, S. (1994). Teaching Language Arts: An Integrated Approach, Minnesota. ED 364900.

Carter, C. (2001). Reciprocal Teaching: The Application of a Reading Improvement Strategy on urban student in High Land Park, Michigan, 1993 - 1995. Innodate Monographs 8 . ERIC, No. ED 456429.

Curran, L. \& Guin, L. \& Marshall, L. (2002). Improving Reading Ability through the use of Cross- Age Tutoring, phono-Graphix, and Reciprocal Teaching. ERIC, No. ED 471073. 


\section{ASPECTS OF READING WEAKNESSES AMONG FIRST CYCLE STUDENT}

IN PRIVATE SCHOOLS IN SULTANATE OF OMAN

Gavelek, J. (1999). Integrated Literacy Instruction, A Review Of The Literature. Center for The Improvement of Early Reading University of Michigan, ED 429310.

Kourea, L., Cartledge, G., \& Mustirao, S .(2007).Improving the reading skills of urban elementary students through total class peer tutoring. Remedial and special education. 28 (2), 95 - 107.

Oczkus, L. (2003). Reciprocal Teaching At Work: Strategies For Improving Reading Comprehension. ERIC. No. ED 4802.

Parker, Richard., Hasbrouk, J; \& Denton, C. (2002). How to tutor students with reading comprehension problems. Preventing School Failure.

Slater, W. \& Horstman, F. (2002). Teaching Reading and Writing to struggling Middle School and High school students: The case for Reciprocal teaching. ERIC, No. EJ. 653731.

Weedman, L. V.(2003). Reciprocal Teaching Effects Upon Reading Comprehension Levels Students in 9 the Grads, Web site; http://www.lib. com/dissertations. 